\title{
Leveling Out the Effect of Sample Runouts on Wear when Testing on the SMT-1 Friction Machine
}

\author{
V.A. Pogonyshev ${ }^{1, *}$, V.E. Torikov ${ }^{1}$, I.A. Mokshin ${ }^{1}$, D.A. Pogonysheva ${ }^{2}$, and A.A. Boiko ${ }^{3}$ \\ ${ }^{1}$ Bryansk State Agrarian University, Kokino, Bryansk Region, Russian Federation \\ ${ }^{2}$ Bryansk State University, Bryansk, Bryansk Region, Russian Federation \\ ${ }^{3}$ Sukhoi State Technical University, Gomel, Belarus
}

\begin{abstract}
The research is aimed at improving the quality of testing the tribotechnical characteristics of materials on the SMT-1 friction machine. Testing the bearing materials according to the disc-pad model may be incorrect due to sample runouts. The aim of this work was to level out the influence of sample runouts on wear and other tribotechnical characteristics of friction units.
\end{abstract}

The most commonly used method of conducting tribotechnical tests of bearing materials for wear is according to the model "rotating disk - fixed pad" using the SMT-1 friction machine [1-7]. The machine design enables continuously speed adjustment of the disk rotation.

Galvanic iron-zinc coatings were used as experimental samples on the surface of the shaft with a thickness of $0.8 \mathrm{~mm}$ and a width of $10 \mathrm{~mm}$, electroplated on the element of cylindrical rollers with a diameter of $49.5 \mathrm{~mm}$ and a height of up to $1.0 \mathrm{~mm}$. The outer diameter of the electroplated discs after grinding was $50 \pm 0.01 \mathrm{~mm}$. The opening of the roller was treated with a reamer having a diameter of $16 \mathrm{~mm}$; the outer surface was finished with a grinding machine before and after coating. A bushing segment with an inner diameter of $50 \mathrm{~mm}$ equal to the outer diameter of the electroplated coating was used as a pad. This method of metal coating does not exclude radial runouts during tribotechnical tests (from 0.05 to $0.10 \mathrm{~mm}$ ).

The disadvantages of this method are the following:

- an uneven coating thickness due to the mismatch of the rotation axes of the friction machine and the grinding machine;

- a large amount of radial runouts during the test $(0.05-0.10 \mathrm{~mm})$; it can lead to a change in the wear mechanism, a significant range of the results of tribotechnical tests.

The authors have proposed a method for reducing the unevenness of the coating thickness [8-11]. The result is achieved by grinding the outer surface of the roller before and after coating on the shaft of the friction machine using a specially made grinding head mounted on the body of the friction machine. The scheme of the grinder for the friction machine 2070 SMT-1 is shown in Fig. 1. The friction machine 1 rotates the roller 2 electroplated with a galvanic coating 3 . The roller is attached to the machine shaft 5 with a

${ }^{*}$ Corresponding author: pog@bgsha.com 
screw nut 4. The grinding stone 6 for grinding the outer surface of the roller before and after the coating is tightened with a screw nut 7 . The grinder electric motor 8 rotates the grinding stone 6 . The grinding head is approached with the help of micrometric screws 10 ; and the position of the grinding stone relative to the coating is controlled by micrometric rulers 9 .

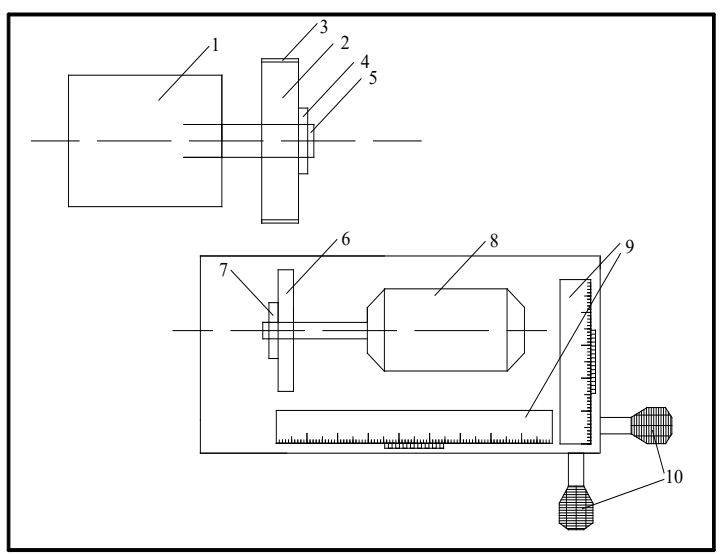

Fig. 1. The scheme of the grinder to the friction machine 2070 SMT-1

The photo of the working grinder is given in Fig.2.

The radial runouts of the roller with and without coating were measured with an ultramicrometer IP-1 at the rotation speed of the shaft of the friction machine of $5 \mathrm{~s}^{-1}$ accurate within $0.01 \mathrm{~mm}$.

The thickness of the coatings was measured with the same device at eight points, turning the disk relative to the axis by $45^{0}$ before each new measurement.

Tests of coatings for friction and wear were carried out on the friction machine 2070 SMT-1 according to the model "rotating disk - fixed pad" under conditions of boundary friction with mineral oil lubricant M8B(SAE20) GOST 10541-78 at a speed of $20 \mathrm{rps}$ and a load of $5 \mathrm{MPa}$. The test time is 1 hour.

To compare the test results, the disc element was ground with the grinding machine (type 3B153U), as well as on the shaft of the friction machine. The results of the value measurements of radial runouts, thickness and wear of coatings, are given in the columns "prototype" and "invention" in Tables 1, 2 and Fig.3. Tables 12 and Fig.3 show that the use of a grinding head combined with a friction machine made it possible to significantly lessen the radial runouts and the unevenness of the coating thickness. This led to a reduction in the range of the results of tribotechnical tests. 


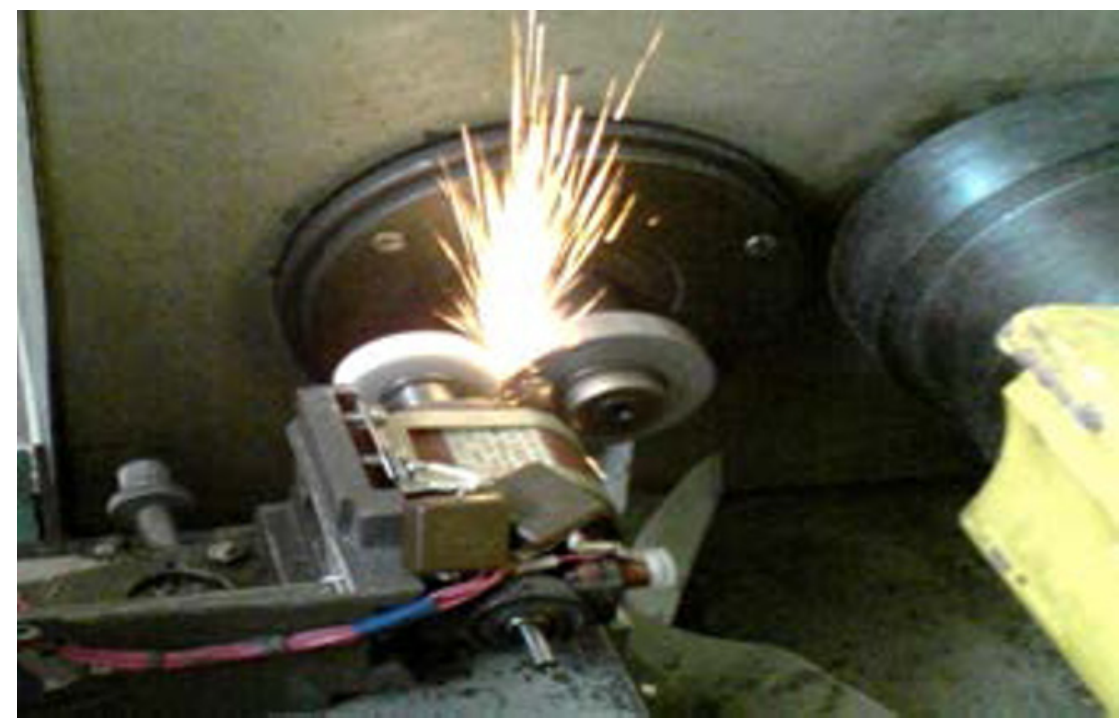

Fig. 2. Photo of the grinder to the friction machine 2070 SMT-1

Table 1. Results of comparative tests of the sample radial runout and the wear rate

\begin{tabular}{|c|c|c|c|c|}
\hline \multirow{2}{*}{ Sample number } & \multicolumn{2}{|c|}{ Radial runout, $\mathrm{mm}$} & \multicolumn{2}{|c|}{ Coating wear, mg } \\
\hline & prototype & invention & prototype & invention \\
\hline 1 & 0.08 & 0.01 & 14 & 16 \\
\hline 2 & 0.07 & 0.01 & 28 & 12 \\
\hline 3 & 0.05 & 0.01 & 32 & 15 \\
\hline 4 & 0.08 & 0.02 & 18 & 14 \\
\hline 5 & 0.08 & 0.02 & 10 & 3 \\
\hline 6 & 0.06 & 0.01 & 4 & 4.5 \\
\hline 7 & 0.04 & 0.02 & 7 & 3.5 \\
\hline 8 & 0.07 & 0.02 & 15 & 2.5 \\
\hline
\end{tabular}

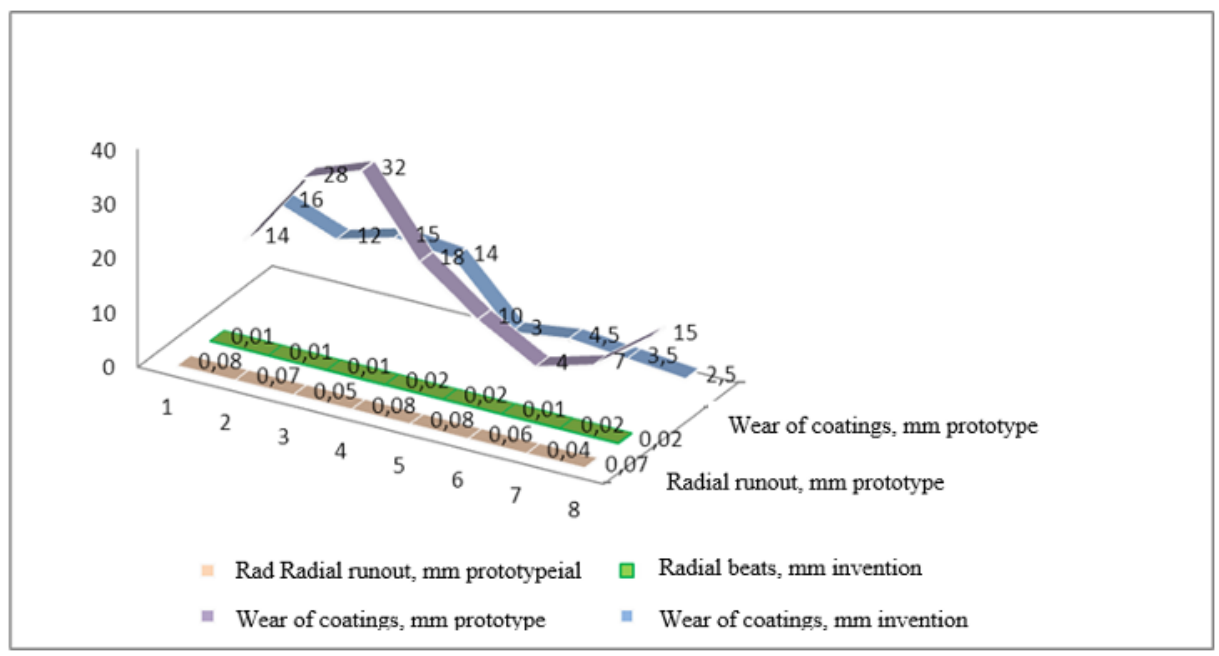

Fig. 3. Dependence of the wear of coatings on the radial beats of the sample 
Table 2. Coating thickness of the test samples variety

\begin{tabular}{|c|c|c|c|c|c|c|c|c|c|c|c|c|c|c|c|c|}
\hline № & \multicolumn{16}{|c|}{ Coating thickness, $\mathrm{mm}$} \\
\hline & \multicolumn{8}{|c|}{ prototype } & \multicolumn{8}{|c|}{ invention } \\
\hline 1 & 0.25 & 0.28 & 0.31 & 0.33 & 0.35 & 0.32 & 0.30 & 0.27 & 0.24 & 0.24 & 0.25 & 0.25 & 0.26 & 0.25 & 0.25 & 0.24 \\
\hline 2 & 0.24 & 0.26 & 0.28 & 0.30 & 0.31 & 0.29 & 0.27 & 0.26 & 0.22 & 0.21 & 0.22 & 0.23 & 0.24 & 0.23 & 0.22 & 0.22 \\
\hline 3 & 0.26 & 0.28 & 0.32 & 0.35 & 0.35 & 0.33 & 0.31 & 0.27 & 0.25 & 0.24 & 0.25 & 0.26 & 0.27 & 0.26 & 0.25 & 0.25 \\
\hline 4 & 0.25 & 0.27 & 0.31 & 0.32 & 0.34 & 0.33 & 0.29 & 0.29 & 0.25 & 0.25 & 0.27 & 0.27 & 0.28 & 0.27 & 0.26 & 0.26 \\
\hline 5 & 0.27 & 0.27 & 0.29 & 0.31 & 0.33 & 0.32 & 0.31 & 0.30 & 0.27 & 0.27 & 0.28 & 0.28 & 0.29 & 0.28 & 0.28 & 0.26 \\
\hline 6 & 0.23 & 0.25 & 0.28 & 0.30 & 0.31 & 0.29 & 0.27 & 0.23 & 0.22 & 0.22 & 0.23 & 0.23 & 0.23 & 0.22 & 0.21 & 0.21 \\
\hline 7 & 0.24 & \begin{tabular}{|l|l|}
0.27 \\
\end{tabular} & 0.29 & 0.32 & 0.34 & 0.31 & 0.29 & 0.26 & 0.23 & 0.24 & 0.24 & 0.25 & 0.25 & 0.24 & 0.23 & 0.22 \\
\hline 8 & 0.25 & 0.29 & 0.31 & 0.34 & 0.36 & 0.33 & 0.30 & 0.28 & 0.25 & 0.25 & 0.26 & 0.26 & 0.27 & 0.26 & 0.26 & 0.25 \\
\hline
\end{tabular}

The method for preparing the surface of metal coatings for wear resistance tests according to the model "rotating disk - fixed pad" implies grinding the surface of the roller before and after electroplating. Its specific feature is the following: in order to reduce the radial sample runouts, the uneven thickness of the coatings and the range of the results of tribotechnical tests, the grinding of the disc before and after coating is carried out directly on the shaft of the friction machine using a specially made grinding head mounted on the frame of the friction machine.

A device for preparing the surface of metal coatings for wear resistance tests according to the model "rotating disk - fixed pad" having an electric motor with a grinding stone fixed to its shaft and a device for performing lengthwise and cross feeding of the grinding stone has got the characteristic to reduce the radial sample runout, uneven thickness of the coatings and the results range of the tribotechnical tests. The grinding device is fixed directly on the frame of the friction machine.

The tests were carried out using the SMT-1 friction machine according to the disc-pad model in two constant modes. The selected test modes were within the operating modes of sliding bearings in the units of agricultural and road vehicles. The friction units were lubricated by touching the lower part of the rotating disc with oil from a special cuvette. M8G1 oil was used as a lubricant. The wear value of the steel parts was determined by weighing them by means of the VLR-200 scales. Measuring the wear of cast-iron pads presented the significant methodological difficulties, since cast iron has the ability to absorb oil, measurement of mass wear is not possible [2]. In some cases the method of artificial bases leads to significant errors, since splitting off the cast iron particles along the contour of the controlled print are possible, which leads to understating of the wear value. Therefore, concurrently with the gravimetric method of artificial bases, the wear value of cast iron samples was measured using profilograms.

The matter is that the discs had a width of $15 \mathrm{~mm}$ and the pad was of $10 \mathrm{~mm}$, so some coating left on the disc that was not subject to wear. The height of the step was determined from the non-worn section to the worn one by the profilograms. To obtain the profilograms, the profilograph 201 was used. At the testing the friction moment is automatically recorded by the KSP-4 potentiometer. The coefficient of friction is calculated by the value of the friction moment. The friction unit disc (iron-zinc coating) - pad (cast iron) works worse than the reverse pair, which is manifested in the setting of metals, the appearance of smoke, a sharp increase in wear and coefficient of friction. It has been found that cast-iron discs treated with the finishing antifriction treatment method have a lower coefficient of friction and wear in the friction unit with a steel pad (steel 45).

The cast-iron samples treated with this method at $\mathrm{P}=30 \ldots 40 \mathrm{H}$ and $\mathrm{N}=150 \ldots 170 \mathrm{rpm}$ had the least wear.

Taking into consideration the wear of a cam and a pusher, the MKF-18U additive does not significantly improve the tribotechnical properties of the friction unit in these operating conditions; and the copper film reduces the wear of the cams and the pusher. The 
experiment proved that the wear of the cam occurs 25 times faster than the pusher. For that reason, the wear of the pads was studied, and the wear of the disc (due to its insignificance) was not taken into account. Moreover, improving the steel coatings with copper films [5-7], the wear of the pads was significantly reduced. The results of the experiments carried out have led to the following findings:

1. Iron-zinc coatings together with a cast-iron pad work more efficiently than the samples made of steel 45 .

2. The application of copper films on steel coatings reduces the wear of steel coatings 10-15 times, and the coefficient of friction 2-3 times. It was noticed at testing that oil is kept much better on the copper films than on steel and steel coatings; thus improving the wear resistance of the friction unit and its tribotechnical properties.

3. Radial runouts have a comparable effect (about 30\%) with the values of the tribotechnical characteristics of the tested coatings.

\section{References}

1. Study of the tribotechnical characteristics of metal coatings by surfacing, electroarc and plasma spraying / V.A. Pogonyshev, P.D. Netyagov, E.N. Samsonovich, G.D. Antsifrov // Friction and wear. 1989. Vol. 10. No. 5. Pp. 909-912.

2. Pogonyshev V.A., Logunov V.V. Increasing the durability of the coating, obtained by spraying and surfacing // Hardening, coating and repair technologies: theory and practice: materials of the 15th International scientific-practical conf. Sankt-Peterburg: Polytechnical publishing house. University, 2013. Pp. 175-178.

3. Pogonyshev V.A. Fretting Wear Physics. Bryansk, 1999. 280 p.

4. Pogonyshev V.A., Romaneev N.A., Panov M.V. Tribological engineering in agriculture. Bryansk: Publishing House of the BSAA, 2010. 480 p.

5. Pogonyshev V.A. Increasing the wear resistance of the reconditioned friction units of agricultural machines by friction application of plastic metal films: Cand. Diss. Absract (Engineering). Kalinin. 1990. 24 p.

6. Panov M.V., Pogonyshev V.A. Hydrophysics. Bryansk: Publishing house Bryansk State Agricultural Academy, 2009. 154 p.

7. Pogonyshev V.A., Logunov V.V. Increasing wear-resistant crankshaft necks by applying plastic metal films. Strengthening Technologies and Coatings.2013. No. 6. P. 47-48.

8. Pogonyshev V.A., Logunov V.V. Mathematical model of damping using plastic metal films // Proceedings of GOSNITI. Moscow, 2013. Vol. 110. Part 1. Pp. 92-95.

9. Procedure and device for preparing surface of metal coating to wear resistance tests: Patent RU 2400726 / Pogonyshev V.A., Bychkova T.V., Ivashkin Ju.A., Artemov A.I., Pleskacheva O.Ju., Panov M.V.; applicant and patent holder: Bryansk State Agricultural Academy, Bryansk State Technical University, appl. No 2008112635/28 01.04.08.

10. Method of vibration damping: Patent RU 2126916 / Pogonyshev V.A., Kharchenkov V.S., Matantseva V.A., Romaneev N.A., Khokhlov A.G.; applicant and patent holder: Bryansk State Agricultural Academy; appl. No 96110840 31.05.96.

11. Pogonyshev V.A. Improving the wear and fretting resistance of machine parts by modifying the surfaces: Doct. Diss. (Engineering). Bryansk. 2000. 268 p. 